\title{
O SUJEITO E O OUTRO NO TRATAMENTO DA TOXICOMANIA
}

\author{
THE SUBJECT AND THE OTHER IN THE TREATMENT OF TOXICOMANIA
}

\author{
Gláucia Brandão de Vasconcelos ${ }^{1}$
}

RESUMO: Esse artigo é resultado de uma pesquisa bibliográfica, realizada com o objetivo de investigar as contribuições da psicoterapia voltada às pessoas que buscam a ressignificação da sua relação com a droga. Como resultado da pesquisa, evidenciou-se que é possível, a partir da queixa clínica e do desejo manifesto do sujeito diante à busca pelo tratamento da toxicomania, contribuir com intervenções que possibilitem a produção de novas subjetivações, ressignificando o papel do objeto droga através do processo de fala e das elaborações fomentadas no âmbito psicoterapêutico, onde se estabelece uma outra noção de sujeito. Conclui-se que as intervenções psicológicas e o setting estabelecido favorecem a ampliação do manejo do sofrimento, possibilitando ao sujeito em tratamento, o rearranjo de suas ações em suas formas de existências.

Palavras-chave: Droga. Toxicomania. Elaboração. Psicologia. Psicanálise.

ABSTRACT: This article is the result of a bibliographical research, carried out with the objective of investigating the contributions of psychotherapy in the care aimed at people who seek the resignification of their relationship with the drug. As a result of the research, it was evidenced that it is possible, from the clinical complaint and the manifest desire of the subject before the search for the treatment of drug addiction, to contribute with interventions that enable the production of new subjectivations, resignifying the role of the drug object through the speech process and the elaborations promoted in the psychotherapeutic context where another notion of subject is established. It is concluded that psychological interventions and the established setting favor the expansion of the management of suffering, enabling the subject under going to be treated with the rearrangement of his actions in his forms of existence.

Keywords: Drug. Drug Addiction. Elaboration. Psychology. Psychoanalysis.

\section{INTRODUÇÃO}

Neste artigo investigaram-se as contribuições da psicoterapia na ressignificação dos sujeitos em situação de sofrimento psíquico, ocasionada pela sua relação com o objeto droga, buscando identificar a importância da expressão da angústia enquanto processo de elaboração. Observou-se

\footnotetext{
1 Graduada em Psicologia pela Faculdades Integradas São Pedro; Pós- graduada em Educação Pobreza

e Desigualdade Social pela UFES; Pós graduada em Dependência Química pela Faculdade Icetec-Futura; Membro da Liga Acadêmica de Psicanálise e Psicopatologia. E-mail: galuvasconcelos@hotmail.com.
} 
que através da livre expressão e de intervenções psicológicas bem fundamentadas, é possível manejar o sofrimento decorrente do uso ou abuso de drogas e transmutar a relação desses sujeitos com a vida e com a droga, ampliando suas percepções e seu repertório de habilidades psíquicas diante de situações adversas que podem remeter ao uso.

O interesse em discorrer sobre esse assunto surgiu de uma experiência no trabalho realizado em um equipamento público de saúde mental em Vitória - ES, que atende a pessoas em uso ou abuso de substâncias psicoativas que estão em tratamento e já passaram pelo período de desintoxicação da droga, e em momento de reorganização da sua identidade há pelo menos quatro meses. O presente trabalho parte do recorte do discurso de pacientes pertencentes ao tratamento em grupo, estável, sem distinção de gênero, com dois encontros semanais, e que conta com no máximo seis participantes. A prática clínica vivenciada aponta como fundamental entender, através da escuta dos diversos dizeres e não dizeres, como e, porque se dá o contato com a droga, ressaltando que o contato de uma pessoa com determinada substância acontece por diferentes razões que vão além do prazer e fuga, sendo essa relação estabelecida através de um contexto biopsicossocial.

Esse tema possibilita um continuum olhar do profissional acerca do fenômeno intitulado como dependência química, denominação essa categorizada pela Organização Mundial de Saúde (OMS) e Classificação Internacional de Doenças (CID Io) entre outras referências a que se compõe, ora no aspecto da saúde, ora no aspecto jurídico, ora no aspecto social, para referenciar o indivíduo em situação de uso ou abuso de drogas que lhe ocasione algum prejuízo, seja na esfera afetiva, cognitiva, funcional, social, psíquica ou física. Entretanto, não adentraremos nessa linha de raciocínio, pois falar do produto droga envolve questões referentes à violências, tráfico, criminalização, discriminação, saúde versus doença, gênero; questões essas relacionadas ainda à lógica perversa do capitalismo, e segundo Foucalt nos apontou muito bem, às relações de Biopoder ${ }^{2}$ e medicalização da vida, onde patologizam-se corpos usuários de drogas. Entretanto, aqui trataremos de discorrer somente sobre o objeto droga na ótica do sujeito em sofrimento psíquico e seu lugar de fala.

Isso posto, é preciso que entendamos a toxicomania sob a ótica psicologia o lugar da fala do sujeito e, ainda, a posição em que ele se coloca enquanto tal.

Para compreender estes papéis nesse espaço de reflexão, foi realizado revisão literária de estudos que trazem como convite a verificação e a legitimação da psicoterapia enquanto reorganizadora da noção de sujeito daqueles que enxergam sua relação com a droga e trazem consigo alguns conflitos oriundos dessa relação.

\footnotetext{
${ }^{2}$ Conjunto de relações de força multilaterais (Foucault, 1999).
} 


\section{Metodologia}

Foi realizada uma revisão de literatura com base nos estudos em livros e artigos publicados que abordam as contribuições das intervenções psicoterápicas no tratamento da toxicomania e na elaboração do sujeito com o objeto droga. Ao estudo foi dado ênfase na abordagem psicanalítica. Os termos pesquisados foram: psicologia, psicanálise, drogas, dependência química, toxicomania. $O$ critério para a inclusão dos artigos foi relevância com o tema; em relação aos artigos levantados. Priorizou-se ano de publicação: estudos dos últimos 30 anos, e que foram publicados em revista das áreas de psicologia e Scielo. Excluíram-se artigos que priorizavam informações sobre drogas relacionadas à questão do gênero ou questões sociais e judiciais decorrentes, por se tratar de um estudo sobre o sujeito em suas subjetivações de uma forma ampla e sem distinções ou que não estavam especificamente relacionados ao assunto abordado. Foi realizada leitura qualitativa e associação de ideias para discussão e conclusão do trabalho.

\section{Fundamentação Teórica e discussão}

\section{O uso de drogas na história e do que se trata}

Compreender historicamente a origem e evolução do uso de drogas na sociedade é de essencial importância de modo a que se compreenda a complexidade da relação do homem com a droga que, importante ressaltar, perdura há séculos. É sabido que o uso de drogas acompanha a cultura da humanidade desde remotos tempos, e estudos científicos e antropológicos remetem a existência das drogas desde a pré-história. Começando pela terminologia da palavra droga, de acordo com Carneiro (2005), a palavra "droga" advém do termo holandês droog, usado para se referir aos produtos naturais relacionados à cura de doenças e da culinária.

A OMS (20oI) propõe, através de uma abordagem biológica, que "droga é toda substância natural ou sintética que introduzida no organismo vivo, pode modificar uma ou mais de suas funções".

Quando se discorre sobre a presença das drogas desde a antiguidade, pode-se pensar para ilustrar este estudo alguns exemplos, como o álcool e o ópio. O consumo de álcool esteve presente como cultura desde a antiguidade e em específico o vinho, que encontra-se como figura fundamental em algumas mitologias, entre elas a cristã, como símbolo do corpo de Cristo e frequentemente citada em diversas passagens de personagens bíblicos; na mitologia grega, onde é representado pela figura do Deus Dionísio e mesmo na Romana, pelo Deus Baco, conforme descrevem Escohotado (1995) e Carneiro (2005). 
Na perspectiva de Velho (1997) a relação das sociedades humanas com estas substâncias, expressa por um lado, uma relação com a natureza e por outro, um processo singular de construção social da realidade. $\mathrm{O}$ autor aponta que a cada tempo em que se consome a droga, ela tem um significado diferente, portanto, é indispensável que se faça a contextualização e que não se estude sobre o uso de drogas isoladamente, visto que todas as tentativas anteriores de explicações genéricas tendem a rotular ou estigmar a questão das drogas (1999, p. 27). Para Toscano Jr. (200I), trata-se de uma presença constante no tempo, associada não apenas à medicina e à ciência, mas também à magia, religião, cultura, festa e deleite.

Assim como o álcool, o ópio foi usado por milênios, remontando à pré-história e também é citado em diversas mitologias, tendo sido por muito tempo extremamente comum e aceito na sociedade europeia ocidental e oriental. Mesmo na contemporaneidade, algumas comunidades xamânicas se utilizam de opióides. A dita "guerra às drogas", tem um contexto sócio histórico antigo, podendo ser tomando como exemplo a China, que enfrentou por duas vezes a Guerra do Ópio no século XIX. Exemplificou-se o álcool e o ópio, entretanto, a morfina, a cocaína, a cafeína, os ansiolíticos e antidepressivos, a maconha, o tabaco, o crack, entre todas as outras substâncias lícitas ou ilícitas, advindas da indústria farmacêutica ou não, são, em dado momento, senhoras de seu tempo, em sua relação com o homem.

$\mathrm{Na}$ contemporaneidade, quando se busca possíveis motivações indutoras ao uso de drogas, estudos científicos e sociais apontam que predisposição genética, contexto familiar e social, facilidades no acesso às drogas, a mídia, incidências de doenças psiquiátricas estão entre os principais fatores. A comunidade científica considera biopsicossocial os fatores que induzem o sujeito ao contato com a droga, perpassando ainda pela curiosidade, festas, influência de pares, fatores estressantes no ambiente laboral, estudantil, familiar, social, desemprego, pouco acesso ao lazer, cultura e serviços de saúde inabilidade para lidar com as próprias emoções e características individuais permitem considerar que a etiologia deste transtorno está, portanto condicionada a fatores multifatoriais.

É sabido, entretanto, salientar que os fatores supracitados estão em paralelo às características da identidade do indivíduo e dos seus modos de subjetivação. Portanto, em relação aos fatores psicológicos que levam o indivíduo ao uso abusivo de substâncias psicoativas, podemos citar Freud (1930; 1996) quando propõe que o recurso às drogas é compreendido como resposta do sujeito ao malestar, que é inerente tanto ao processo de formação das sociedades e culturas, quanto à própria constituição psíquica do ser humano. Diante dessa pressão exercida pela civilização, e pelas instâncias repressoras da psique, instaura-se um mal-estar que apenas pode ser suportado através de 
medidas paliativas. Dentre as medidas paliativas existentes, Freud considerou o recurso aos tóxicos como o método mais grotesco, contudo, e paradoxalmente, o mais eficaz para evitar o sofrimento humano, pois influencia o nosso corpo e altera sua química de forma a nos tornar insensíveis à nossa própria desgraça.

Bucher (1996) afirma existir droga a priori; essas são atividades simbólica e um conjunto das motivações no sujeito que transformam uma substância psicotrópica em droga, levando à sua integração de maneira estável na sua estrutura motivacional; propõe a ideia do sujeito em posição ativa, não necessariamente apresentando alguma questão patogênica, mas uma pessoa que como todas as outras, se utiliza de símbolos para se comunicar consigo mesmo e com o meio. Tais símbolos remetem à subjetividade, portanto, à identidade do indivíduo, que não é adquirida em definitivo e é constantemente posta em questão a cada interação. Dessa forma, uma substância psicoativa se torna droga provocando dependência dentro de um determinado contexto de relações entre atividades simbólicas e o contexto em si (p. 132). O autor ainda propõe que, a partir disso, é devido estudar o que o sujeito em sua relação com a droga considera indispensável à satisfação de necessidades no âmbito afetivo, cognitivo, social e cultural (Bucher et al.; 1992: 160-162).

\section{Transtorno relacionado ao uso de substâncias}

O DSM, Diagnostic and Statistical Manual ou Manual de Diagnóstico e Estatística, atualmente na sua quinta versão (DSM-V), abrange os transtornos mentais elaborados pela associação americana de psiquiatria. Ele define o transtorno por uso de substâncias e o transtorno induzido por substâncias, apontando que todas as drogas que são consumidas em excesso têm em comum a ativação direta do sistema de recompensa do cérebro, o qual está envolvido no reforço de comportamentos e na produção de memórias. A ativação do sistema de recompensa é intensa a ponto de fazer atividades normais serem negligenciadas. Em vez de atingir a ativação do sistema de recompensa através de comportamentos adaptativos, as drogas de abuso ativam diretamente as vias de recompensa. Indivíduos com baixo nível de autocontrole, o que pode ser reflexo de deficiências nos mecanismos cerebrais de inibição, podem ser particularmente predispostos a desenvolver transtornos por uso de substância, sugerindo que, no caso de determinadas pessoas, a origem dos transtornos por uso de substância pode ser observada em seus comportamentos muito antes do início do uso atual de substância propriamente dito.

Isso posto, cabe ressaltar que o DSM V, em sua versão atual, exclui o termo dependência química, utilizando o termo "transtorno por uso de substâncias", que pode ser categorizada em leve, moderada e grave, de acordo com os critérios observados e preenchidos, incluindo na sua atualização 
a abstinência de cafeína e de maconha. A OMS (200I) destaca:

A dependência química deve ser tratada simultaneamente como uma doença médica crônica e como um problema social. Pode ser caracterizada como um estado mental e, muitas vezes, físico que resulta da interação entre um organismo vivo e uma droga, ocasionando em uma compulsão por tomar a substância e experimentar seu efeito psíquico e, às vezes, evitar o desconforto provocado por sua ausência.

Sobre o termo Toxicomania, denominação usada como tema deste estudo, Ribas (2009) cita que, de acordo com Olievenstein, é uma situação psicoafetiva estruturada, buscando encontrar um estado almejado, que deve funcionar como euforizante das satisfações que o indivíduo não encontra na vida cotidiana.

O termo toxicomania, proposto por Santiago (200I) advém do discurso proferido pela psiquiatria, que em meados do século XIX passa a considerá-lo isoladamente como categoria clínica específica, relacionada à inclinação impulsiva e aos atos maníacos. Fazendo alusão aos dizeres da psiquiatria, o autor postula que do ponto de vista psicanalítico, é efeito de um discurso.

Sob a vertente psicanalítica, a definição do termo toxicomania está em segundo plano em detrimento ao papel e ao lugar que a droga tem na vida do toxicômano, visto que, quando o termo droga surge no discurso do paciente, é notório camadas que apontam uma suposta relação do sujeito com o mal-estar. Para J-A. Miller (1995), a definição da toxicomania através da psicanálise, aponta que não é uma definição do termo e sim uma tentativa de definição da droga enquanto tal; que na experiência analítica nos perguntemos menos pela toxicomania que pela droga em sua relação com o sujeito.

No olhar psicanalítico, o sujeito faz a droga e não o contrário. Assim sendo, cada sujeito possui singular relação com seu objeto droga e ao psicanalista, cabe atentar-se para o que se escuta e quem se escuta, atentando-se a como o uso de droga entra e aparece em cada discurso de linguagem, sendo dessa forma o sujeito estruturado dentro dessa e não na terminologia toxicomania, pelo único fato de usar drogas.

Em relação ao termo toxicomania/toxicômano sob o olhar psicanalítico, Santiago aponta:

Para a psicanálise esse termo tem um valor identificatório. Com efeito, esse significante pode tornar-se, para certos sujeitos, objeto de uma escolha. Ser toxicômano consiste então num recurso diante do impasse de uma neurose, ou mesmo de uma psicose. Esse aspecto identificatório manifesta-se frequentemente mediante o enunciado: "Sou toxicômano" (2001, p. 185).

Sobre a terminologia posta em discurso, Miller escreve:

Em todos os casos, a possibilidade de análise passa pelo esforço de desfazer a identificação bruta "eu sou toxicômano". Em consequência, desde o ponto de vista da experiência analítica, tudo que reforce essa identificação está contraindicado (1992, p. 20). 
Isso posto, dizer "sou toxicômano" é um discurso que se enquadra dentro de uma lógica pejorativa, midiática e capitalista ao qual não cabe ao psicanalista se prender.

\subsection{Contribuições do profissional}

“É o mundo das palavras que cria o mundo das coisas" (Lacan, 1998, p. 277).

O campo de produção do conhecimento, e as práticas profissionais existentes na psicologia são amplas, o que acarreta uma associação entre práticas e referenciais teóricos, fazeres e contextos específicos ou lugares de inserção do profissional. Deve-se considerar que a diversidade da psicologia vai além dos conceitos das áreas, pois esta inclui uma diversidade teórico-metodológica que fundamenta a prática de intervenção e pesquisa profissional (BASTOS, 2010).

Gianesi (2005) considera que, no que tange à ótica psicanalítica, pondera-se que a manifestação toxicomaníaca não é exclusiva de qualquer uma das três estruturas propostas psicose, neurose ou perversão - o fazer uso problemático de drogas, e então serem classificados, a partir da referência médica, como quem sofre de transtorno por uso de substâncias. A estrutura, entretanto, é logicamente anterior a qualquer manifestação, e surge do momento fundante do sujeito. Assim sendo, o psicanalista autoriza-se a afirmar que cada sujeito, estruturado segundo sua já constituída forma de organização do desejo, possui singular relação com as drogas - está sempre amarrada ao modo estrutural (p.127).

Ao se abordar o termo desejo, parte-se da ideia de desejo enquanto pulsão. Desejo enquanto zona nebulosa, conflito, algo não protocolar. O Desejo aqui inserido no contexto da toxicomania revela algo pulsional. E da pulsão, o sujeito vai à repetição. E em repetição podemos pensar no esforço do sujeito para encontrar o objeto, o ritual prazeroso quando encontrado, pondo fim à angústia - a não primária. No que se refere ao sintoma, no âmbito da toxicomania onde o discurso-queixa droga aparece frequentemente, do que se trata esse significante, na vertente psicanalítica? O que se quer dizer com isso na ótica psi, que se contrapõe ao mesmo termo enquanto conceito de doença?

O sintoma é o trabalho de todo sujeito para dar conta do Real. Assim, não deve ser dissociado do sujeito, algo que deve ser modificado, mas não arrancado do sujeito, por ser fundamental em sua estrutura (Ocariz, 2003, p. 137). Ou como propõe Raíces:

Se uma pessoa entra embriagada ou drogada no consultório de um psicanalista, rapidamente se poderia diagnosticar que o sintoma que se apresenta é sua embriaguez. Porém, isso é assim visto pela medicina ou pela ordem social. Não sabemos se isso será ou não um sintoma para uma psicanálise singular” (I992, p. 66).

Nesse sentido, portanto, o sintoma pode ser pensado como um anúncio do passado do sujeito, 
e como ele se relaciona com aquilo. Um prognóstico do que foi até este momento sua história de vida e ele levou muito tempo para construir. Além da dor nesse sintoma, existe também uma satisfação pulsional, e devido a essa ambiguidade, o sujeito se apresenta resistente em prescindir deles.

Nessa linha de raciocínio, Conde (2008) propõe: É interessante notar que o sujeito se sustenta não em um sofrimento, mas em uma satisfação. Por isso, para o sujeito é tão difícil abdicar do sintoma, pois ele manifesta, mesmo que invertidamente, a sua via de contentamento e sustentação (p. 64).

Laia (2008) aponta que sintoma não é um sinal de uma doença, como habitualmente se pensa a partir da ordem médica, mas um fenômeno subjetivo constituído pela realização deformada do desejo. Nesse sentido, ele é aquilo que mescla restrição e satisfação, interdição e gozo, pois, se há alguma realização de desejo, esta se dá de maneira enviesada. Logo, o sintoma é para o sujeito, em simultâneo, aquilo que não anda bem, já que lhe causa sofrimento; mas também aquilo que lhe cabe bem, já que ele passa a gozar e se instituir com seu sintoma. Assim, ele é, com efeito, problema e solução.

Cabe salientar ainda que a perspectiva do tratamento analítico não visa a eliminação dos sintomas, mas a ajudar o sujeito a encontrar uma nova forma de lidar com aquilo que o constitui. Assim podemos pensar no sujeito neurótico. Essa estrutura é dele e a escuta deve ser cautelosa. $\mathrm{O}$ que se elimina é o modo cronificado do sujeito lidar com o modus operandi a qual funciona sua neurose ou sua compulsão, ou seja, a partir do conhecimento ou da compreensão de qual é e onde se inicia sua angústia primária recalcada. No recalque, o sujeito passa a reclamar dos sintomas que sente e não de sua causa. Portanto, é preciso respeitar esse sintoma até que o sujeito, através da linguagem, elabore, ou seja, visto que, suas resistências cederam, e lembranças dolorosas agora são ecordadas e vivenciadas, o sujeito segue, portanto com menos sofrimento ou transmuta antigas percepções sobre tais lembranças. Ainda sobre sintoma, sob a ótica psicanalítica:

A palidez de uma cara, uma tosse seca, mãos suando, um estado tenebroso, uma
obesidade notória, fumar maconha, estar bêbado, não é equivalente nem se traduz
em sintoma para a psicanálise. É necessário que o sujeito se refira a ele enquanto
sujeito dividido, mais ainda, que transforme esse dado em pergunta, que o leve a
questão pessoal (RAICES,1992, p. 72).

Lacan, citado por Conde (2008), revela que existe nesse limite um sofrimento e uma satisfação. Ele se refere ao sintoma como sentido na tentativa de tamponamento da falta fundamental, do fora do sentido, que a língua e o significado não conseguem, recobrir. O sintoma pode ser compreendido como resultado de uma estrutura marcada por uma falta, representando a verdade que aponta para essa falta inerente. Aí residiria com o aspecto 'incurável' do sintoma (p. 67).

Podemos assim entender esse apontamento, através da fala representada abaixo, verbalizada 
pelo sujeito em análise:

“-Eu gosto de todo o ritual que antecede meu uso, de contemplar o cachimbo, do preparo, de olhar a fumaça, o formato dela. O ritual do preparo me dá tanto prazer quanto o uso. F.M'

“- Às vezes, sem perceber eu tento prolongar meu tempo abstinente quando sei que vou fazer uso. Depois é a curtição e a brisa e depois a ressaca moral, e depois, tudo de novo" L. R

Ainda sobre repetição dos sintomas, Pimenta (2014) propõe que essa situação de desamparo acompanha o sujeito por toda a vida, e para lidar com esta adversidade, surge a substância psicoativa. Diante disso, o toxicômano enfrenta dificuldades ao encarar a falta, assim como lida intensamente com seus objetos, não permitindo espaço à falta e ao vazio, passando de um objeto de dependência a outro. Assim dá-se o movimento de repetição em busca da substância. A repetição relaciona-se à falta ao objeto, possibilitando que o indivíduo reencontre o objeto perdido.

“[...] Eu troquei o uso da maconha pela prática da atividade física, mas virou outra compulsão. Eu nadava pela manhã, fazia corrida, boxer à tarde, a noite ia pra academia fazer lutas, até a exautão. Mas sei lá, falta algo ou sou eu que tenho que aprender a entender que a vida é cinza [...]” L.V

Segundo Raíces (1992), na análise de um toxicômano, aquilo que retorna repetitivamente no curso das sessões, é toda sintomatologia significante do sujeito, e isso como em toda análise" (Idem, p. 75). O autor ainda faz o seguinte apontamento:

Existe possibilidade de transformação do sintoma, contanto que isto queira dizer que ele se deve a efeitos de mudança de posição do sujeito em relação à verdade que entranha seu sintoma (Raíces, 1992, p. 74).

Frankl (20II) propõe que o ser humano é permeado em profundidade e em instância culminante, não pela vontade do poder, nem tampouco pela vontade do prazer, mas pela busca do sentido:

[...] vontade de sentido pode ser definido como o esforço mais básico na direção de encontrar e realizar sentidos e propósitos [...] o prazer, mais do que a finalidade dos esforços humanos, é, de fato, o efeito da realização de sentido. O poder, por sua vez, mais do que um fim em si mesmo, constitui, na verdade, um meio para um fim (FRANKL, 20II, p.5o).

Seguindo esse ponto de vista, podemos pensar que, em função da vontade de sentido, o sujeito realiza a busca para essa realização e se move para o encontro. $O$ que o arrasta? $O$ que ele reivindica quando usa a droga? É vontade de potência, de poder, de sentido? Como entende a ausência de sentido? Quais são suas angústias? De que forma as elabora? Assim, é possível pensar na droga como objeto do desejo e não como sintoma. Num discurso psicanalítico, o sintoma trata-se da queixa que ele traz em seu discurso, quando ela se apresenta como desejo incômodo por um sujeito dividido. 
No que concerne a práxis do profissional, quando pensamos em lugar da droga na vida do sujeito, deve-se inicialmente nos questionarmos como pensamos a vida. Vida em fragmentos ou em sua plenitude? Esses são questionamentos que devem mover o profissional em direção ao pensar sobre a estrutura do sujeito antes do seu contato com a droga.

É importante salientar que a relação do sujeito com sua substância de preferência é única, suas percepções e os afetos atravessados na ocasião dos atendimentos psicoterapêuticos são singulares, assim como cada um encontra-se num determinado momento em relação à disponibilidade de repensar seus modos de vida, devendo o profissional entender as diferentes defesas e acolher e respeitar as diversas formas de expressão.

Nesse sentido, é notório que se lança mão de observar a diferença entre droga como tema central na vida ou sujeito como pano de fundo, cabendo ao profissional se questionar o que significa ambas as questões e adiante, se questionar em relação a sua própria noção de realidade. Valendo-se disso, compreende com mais clareza as resistências do paciente. Partindo dessas inquietações que perpassam pela prática clínica, pode-se pontuá-las, contribuindo com a elaboração de conflitos psíquicos desses sujeitos.

Diante disso e ainda sobre a elaboração através da linguagem, Lacan (1998) sugere que a psicanálise dispõe de apenas um meio: a fala do paciente (p. 248). A esse respeito cita que a arte do analista deve consistir em suspender as certezas do sujeito até que se consumam suas últimas miragens. E é no discurso que deve escandir-se a resolução delas (p. 253).

\section{Considerações finais}

Com base no percurso teórico explanado, e, em paralelo à escuta clínica dos sujeitos aqui apresentados como público-alvo deste estudo, pode-se confirmar ser possível ressignificar o modus operandi desses sujeitos em suas relações e nas suas formas de se afetar pela vida através do espaço de fala proposto no âmbito psicoterapêutico. Tal oportunidade de fala, muitas vezes não encontrada no decorrer de suas histórias de vida, se valida na formulação de estratégias da ampliação do manejo de sentimentos como prevenção do retorno ao uso e na manutenção da abstinência.

Cabe ao profissional lançar mão de técnicas psicoterápicas que possibilitem a plasticidade e o exercício das habilidades psíquicas desses sujeitos, visto que a construção da subjetividade não se faz somente no abstrato. O psicodrama, a elaboração de contos, escrita, filmes são elementos simbólicos que, além da fala e da escuta também do não dito, contribuem na produção de novas subjetivações e consequentemente, desejos mais próximos do real no que diz respeito à cura do desconforto posto em discurso. 
Em um ambiente em que o sujeito sinta-se confortável para exercer o seu lugar de fala e relatar sua história de vida, anseios e desejos que antecederam ou sucederam o contato com as drogas, cabe ao profissional trazer à tona, o questionamento - sem confrontos - do lugar da droga, se pano de fundo ou tema central, possibilitando que o sujeito seja livre para discorrer sobre o sentido de suas próprias vivências. Sob a luz do referencial teórico que utiliza, deve reconhecer e entender as resistências do paciente e lançar mão da sua prática clínica embasada no arcabouço de seu referencial, realizando intervenções que possibilitem a abertura para a construção do vínculo e a partir disso, atendê-lo em sua demanda.

Diante do que foi exposto, entende-se que a psicoterapia, neste estudo à luz da teoria analítica, auxilia o sujeito a perceber a sua relação com a droga e o que de fato se traduz em sintoma e a partir disso, estabelecer relações outras que perpassem pelo seu desejo, seja o de controle sobre o uso da droga, redução de danos ou abstinência completa.

A escuta não é uma habilidade inata, ela é adquirida, exercitada, ampliada e validada no cotidiano. O desejo pela cura do suposto sintoma e o feedback oferecido pelo profissional ao sujeito, passíveis de promover a plasticidade das percepções desses indivíduos são fundamentais no processo psicoterapêutico. Deve o setting e a linha de trabalho se dê sem regras rígidas mediante ocasionalmente falas que indiquem a contemplação da droga ou que sinalizem o retorno ao uso, atentando-se o profissional para que não lance mão de discursos, provido de patologização, favorecendo uma escuta empática, contudo fomentando questionamentos que porventura promovam incômodos necessários para produção de novas subjetivações. Tal proceder é importante para que os resultados que se esperam da clínica possam ocorrer, salientando que a estrutura psíquica do sujeito em tratamento antecede ao seu contato com a droga. Dessa forma, partindo na microcultura de cada um, o elaborar sobre si e sua posição enquanto sujeito, a noção do outro, o que o constitui, e o que move sua falta e seus desejos, é possível exercer novos sentidos de existência em sua totalidade de afetos.

\section{REFERÊNCIA}

AMERICAN PSYCHIATRIC ASSOCIATION. Manual diagnóstico e estatístico de transtornos mentais: DSM-5. Porto Alegre, RS: ArtMed, 2014.

BASTOS, A.; GODIM, S. O trabalho do psicologo no Brasil. Porto Alegre: ArtMed, 2010.

BUCHER, R. e Lucchini, R. À Procura de uma abordagem interdisciplinar da toxicomania. In: Drogas e Drogadição no Brasil, Bucher, R. Porto Alegre, Artes Médicas, 1992, p. 181-204.

BUCHER, R. Drogas e Sociedade nos Tempos de AIDS, Brasilia, Editora UnB, 1996, 132pp. 
CARNEIRO, H. Transformações do significado da palavra "droga": das especiarias coloniais ao proibicionismo contemporâneo. In: VENÂNCIO, R. P.; CARNEIRO, H. (Org.). Álcool e drogas na história do Brasil. São Paulo: Alameda; Belo Horizonte: Editora PUCMinas, 2005. p. 1I-27.

CONDE, H. O sintoma em Lacan. São Paulo: Escuta, 2008.

CONTE, M. Psicanálise e redução de danos: articulações possíveis. Revista da Associação Psicanalítica de Porto Alegre: 2004; (25): 23-33.

ESCOHOTADO, A. Historia general de las drogas. 3. ed. rev. aum. Madri: Alianza, 1995. 3 v.

FRANKL, V. E. Em busca de sentido: um psicólogo no campo de concentração. São Leopoldo: Sinodal; Petrópolis: Vozes, 1991.

FREUD, S. Edição standard brasileira das obras psicológicas completas. Rio de Janeiro: 1996.

FREUD, S. O mal-estar na civilização, v. XXI, 1930, p.67-153.

FOUCAULT, M. Em defesa da sociedade: curso dado no Collège de France (1975-1976). São Paulo: Martins Fontes, 1999.

GIANESI, A. P. Psychê, São Paulo , v. 9, n. 15, p. 125-138, jun. 2005. Disponível em: http://pepsic.bvsalud.org/scielo.php?script=sci_arttext\&pid=SI415-

I138200500o10ooro\&lng=pt\&nrm=iso>. Acesso em 30 maio 2020.

LACAN, J. O Seminário, livro 17: o avesso da psicanálise. Rio de Janeiro: Jorge Zahar, 1992.

LACAN, J. Função e campo da fala e da linguagem em psicanálise. In: J. Lacan, Escritos (V. Ribeiro, trad., p. 248-253). Rio de Janeiro: Jorge Zahar, 1998.

LAIA, S. O sintoma como problema e solução. aSEPHallus; 3(6): 64-72, maio-out. 2008. Biblioteca responsável: BRII94.I

MILLER, D. As três transferências. In: . Clínica lacaniana: casos clínicos do campo freudiano. Rio de Janeiro: Jorge Zahar, 1989. [ Links ]

MILLER, J. A. Para una investigación sobre el goce autoerótico. In: SINATRA, Ernesto; SILLITTI, Daniel; TARRAB, Mauricio (comp). Sujeto, Goce y Modernidade : Fundamentos de la Clínica. Buenos Aires: Atuel-TyA, 1992. vol. I. [ Links ]

ORGANIZAÇÃO MUNDIAL DE SAÚDE. Classificação estatística internacional de doenças e problemas relacionados à saúde. São Paulo, SP: Edusp, 20or.

OCARIZ, M. O sintoma e a clínica psicanalítica. São Paulo: Via Lettera, 2003.

PIMENTA, A. C. O tempo em Freud. Estud. psicanal., Belo Horizonte, n. 4I, p. 59-66, jul. 2014 . Disponível em

〈http://pepsic.bvsalud.org/scielo.php?script=sci_arttext\&pid=Soroo-

$34372014000100006 \& \operatorname{lng}=\mathrm{pt} \& \mathrm{nrm}=$ iso $>$. Acesso em 30 maio 2020. 
RAÍCES, G. La Forma del Síntoma en la Drogadicción. In: SINATRA, Ernesto; SILLITTI, Daniel; TARRAB, Mauricio (comp). Sujeto, Goce y Modernidade : Fundamentos de la Clínica. Buenos Aires: Atuel-TyA, 1992. vol. I.

RIBAS VR, et al. Personalidade do dependente químico. Revista de Neurobiologia. 2009 [acesso em II mai. 2020];72(3):65-73. Disponível em: http://www.neurobiologia.org/ex_2009.3/Revista\%20Neurobilogia 72(3)2009\%20(Cap.7)(OK).pdf

SANTIAGO, J. A droga do toxicômano: uma parceria cínica na era da ciência. Rio de Janeiro: Jorge Zahar Editor, 20or.

TOSCANO Jr., A. Um breve histórico sobre o uso de drogas. Em S. Seibel \& A. Toscano Jr. (Eds.). Dependência de drogas (pp. 7-23). São Paulo: Atheneu, 200I.

VELHO, G. Drogas e construção social da realidade. In: Baptista M; Inem C, organizadores. Toxicomania, abordagem multidisciplinar. Rio de Janeiro: NEPAD/UERJ: Sete letras, 1997.

VELHO, G. A dimensão cultural e política do mundo das drogas. In: Zaluar A., organizadora. Drogas e cidadania: repressão ou redução de riscos. São Paulo: brasiliense; 1999. p.23-29. 